Article

\title{
Economic Framework of Smart and Integrated Urban Water Systems
}

\author{
Neil Grigg
}

check for

updates

Citation: Grigg, N. Economic Framework of Smart and Integrated Urban Water Systems. Smart Cities 2022, 5, 241-250. https://doi.org/ $10.3390 /$ smartcities5010015

Academic Editors: Isam Shahrour, Fateh BELAID and Véronique FLAMBARD

Received: 28 January 2022

Accepted: 28 February 2022

Published: 2 March 2022

Publisher's Note: MDPI stays neutral with regard to jurisdictional claims in published maps and institutional affiliations.

Copyright: (C) 2022 by the author. Licensee MDPI, Basel, Switzerland. This article is an open access article distributed under the terms and conditions of the Creative Commons Attribution (CC BY) license (https:// creativecommons.org/licenses/by/ $4.0 /)$.
Department of Civil and Environmental Engineering, Colorado State University, Fort Collins, CO 80524, USA; neilg@engr.colostate.edu

\begin{abstract}
Smart and integrated urban water systems have important roles in advancing smart cities, but their contributions go much further by supplying needed public services and connecting other sectors to meet sustainability goals. Achieving integration and gaining access to financing are obstacles to implementing smart water systems and both are implicit in the economic framework of smart cities. Problems in financing the start-up of smart water systems are reported often. The local and diverse nature of water systems is another barrier because an approach that works in one place may not work in another with different conditions. The paper identifies the challenges posed by the economic framework and provides examples from four cities with diverse characteristics. It outlines pathways to advance implementation of smart water systems by improving control strategies, advancing instrumentation and control technologies, and most of all, to help transform cities by raising customer awareness and trust through reliable and useful water information.
\end{abstract}

Keywords: urban water; smart systems; automation; integrated management

\section{Introduction}

Smart cities have many interrelated parts, and their water systems provide essential functions by supplying needed public services and connecting other sectors with water to aid them in meeting economic, social, and ecological goals. To play these roles effectively, urban water systems should be integrated and take on smart attributes [1]. However, while technological aspects of smart urban water systems are impressive, the systems face challenges to achieve integration, employ smart technologies effectively, and sustain adequate financing sources [2].

Achieving integration and gaining access to adequate financing are principal obstacles to advancing the state of the art of smart urban water systems. While they provide multiple types of services to diverse stakeholders and are vital to cities, they confront financial challenges caused by their multiplexed economic framework. Managing these challenges is complex in cities with decentralized power structures, especially considering issues of affordability and financial limitations.

The paper describes the economic framework of smart water systems and smart cities, and it explains the resulting incentives and controls that it imposes on them. It also identifies challenges the systems face, and it outlines future directions to help advance the implementation of smart water systems in smart cities. The future directions go along three lines. One is improvement in control technologies, which is the main topic that is discussed by researchers studying smart water systems. A second is the advancement of instrumentation and controls, which is driven mainly by commercial incentives. Most significant, however, is the third line, which is about how customers use smart water information to help transform cities.

Several brief case studies of smart urban water systems and integrated approaches are summarized as examples of current situations. These were selected from a growing inventory of case studies that have been made available through recent studies of the 
International Water Resources Association [2]. The selected cases illustrate a leading-edge city (Singapore), a new smart city in Korea (Paju), a growing medium city in the western United States (Fort Collins), and a large city in Mexico with a very limited water supply (Juarez). While the case citations are brief, they range across the major issues along the three lines of discussion, advancing technologies, new control methods, and customer interactions in urban areas.

Interest in smart water systems is advancing rapidly, but their implementation and success will be shaped more by economic and social forces than by advances in technology. The literature about smart water systems mainly focuses on examples of new technologies, and this paper aims to focus more directly on the economic forces that must be confronted by system managers to facilitate improved urban water services.

\section{Urban Water Systems}

Urban water systems are conglomerates of the infrastructures and operating controls of water supply, wastewater, stormwater, and recycled water systems [3]. They serve the social, constructed, and natural subsystems of living cities and they connect elements of these subsystems through interdependences [4]. For example, water supply connects to public safety by providing standby fire protection, stormwater systems can add to open space and recreational opportunities, and urban water systems draw supplies from ecosystems and can in turn nourish them.

This general perspective explains how water interacts with other subsystems, but a city is a system of systems, and it requires more information to explain how urban water systems work and are controlled. A concept for the interdependences among water supply, wastewater, and reclaimed elements is shown in Figure 1, and stormwater systems can be shown to cut across these as they involve entire cities. Stormwater harvesting can be added to the diagram, as well as the biosolids management that results from wastewater treatment.

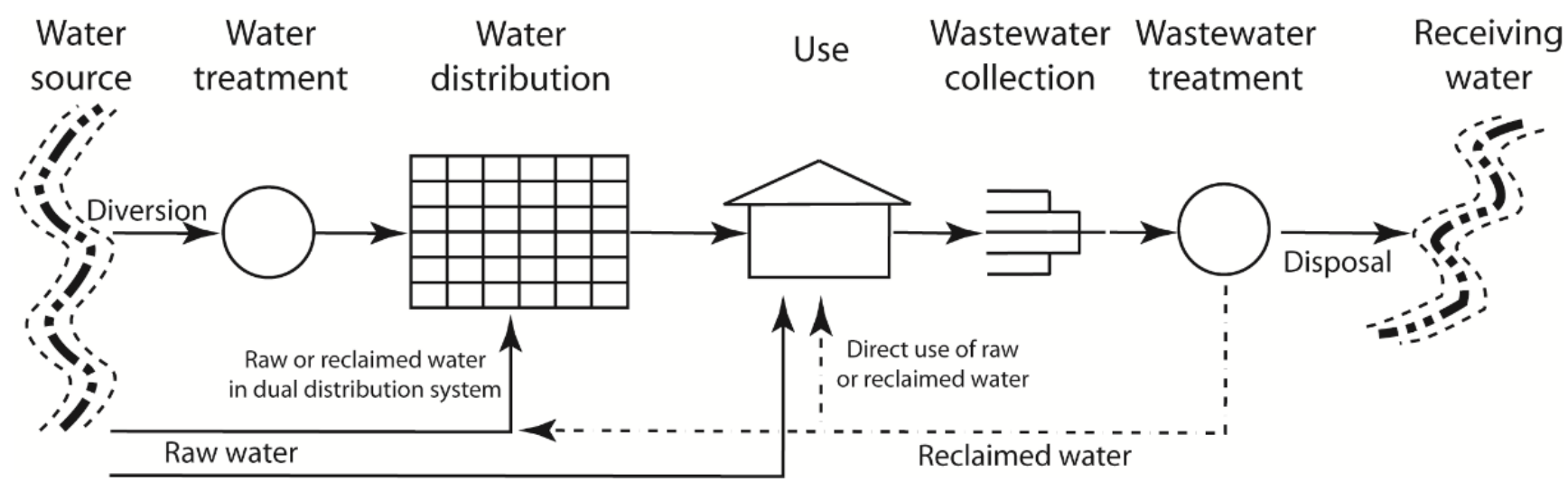

Figure 1. The urban water system.

The urban water system works with raw water diverted and conveyed to treatment, distribution, and to users. Wastewater is collected, treated, and discharged to the receiving stream. Biosolids (or sludge) are dewatered, digested, and disposed of. The stormwater system traverses the city to convey diffused waters, some of which end up in the collection system. Water can be recycled from the wastewater or stormwater system, and raw water can be used directly for purposes such as fire suppression or landscape irrigation.

Integration of urban water systems requires cooperation among the management structures for the separate services. This can be formal, as in placing all services in a single organizational unit, or it can be informal, with cooperation occurring on an ad hoc basis. Formal integration requires a comprehensive approach that includes diversifying sources, protecting water at its source, and integrating operations for water storage, distribution, treatment, recycling, and disposal. This requires that the systems are operated as one utility to facilitate efficiencies like the recycling of wastewater or reducing water footprints. 
Informal integration is much weaker and depends on incentives as well as opportunities for joint work [5].

As urban water systems are nested within the economic, social, and natural systems of cities there are several facets of integration. One integrates the services, such as when the separate services are operated as one utility. Another facet of integration is between the utilities and the external water environment of the streams and aquifers in and around the city. The urban water system impacts the interflows between ground and surface water and the heat island effects in cities, as well as flood plain health and urban ecology. A test for the effectiveness of integration is whether it enables the city to reach net-zero impact status in providing water, preventing pollution, and sustaining urban ecology.

\section{Why Integration Is Needed}

Integration among the separate urban water subsystems is a logical partner to smart systems. Application of controls to the separate water systems has been evolving for decades, but without integration, the efforts will fall short of addressing the major issues that cities face. This reality is widely recognized in the water industry and among urban leaders, and concepts such as One Water are emerging to develop appropriate strategies [6-8]. As an example, one of the cases cited here, the city of Singapore, faces the need to develop a total One Water approach if it is to meet its water needs in the future. Another of the cases, Juarez, which also faces a severely limited water supply, is addressing its smart water system with a different approach.

Integrated urban water resources management through the One Water approach has the potential to affect the shape and functionality of cities [9]. If the One Water approach is to achieve its goals, it must provide customers with integrated information to avoid confusion. For example, customers would not tolerate one message about water use and another about wastewater, especially when they are confronted with so many new categories of information in today's world. If integration can give people a sense of living in a total water environment, they will be more likely to accept a bill for services that pays for all systems involved. They should be informed how smart systems are improving efficiencies through combinations of services with multiple use facilities, for example, detention ponds and stormwater harvesting. Integration can improve information flow in different ways and, if handled effectively, has the potential to improve customer trust in utilities. Another important advantage of integrated approaches is to protect the urban water ecology, which can be built into the combined system to minimize water withdrawals and protect water quality and species $[10,11]$

\section{Smart Water Systems in Smart Cities}

A smart urban water system would join the constellation of other smart systems in a smart city, which use computer controls and information to collect data, use that data to improve operations, and communicate with citizens about all aspects of their lives in the cities [12]. In a smart city, a smart integrated urban water system would feature infrastructure controls, collection of system and user information, application of the information to control water operations and to inform citizens, and it would be available for emergency management.

The concept is illustrated in Figure 2, which shows a system to be controlled and actuators to implement controls based on decisions informed by models and data. The data collection function informs system operators and users as well. Data from the system can be used for operations and troubleshooting. Emergency information can be sent to the actuators.

The concept has evolved from the early supervisory control and data acquisition (SCADA) and control systems to today's smart concept [13]. More specifically, prior to the evolution of smart systems, the concept would have not included the transmission of data shown by the dotted lines stemming from the general flow of information and control 
commands. So, the ability of the smart system to provide the information for operations, customers, and emergency management comprises the most promising new feature.

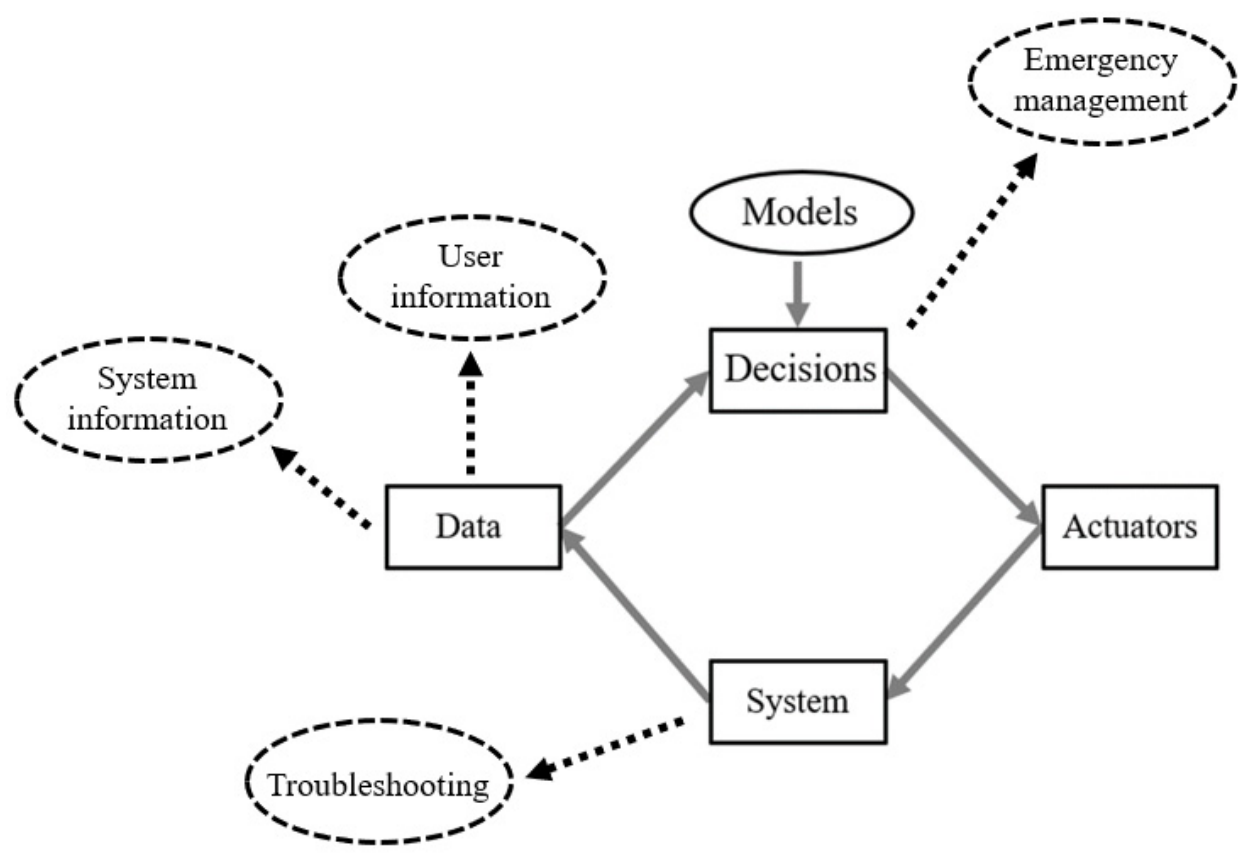

Figure 2. Systems control and information interfaces.

These features of smart water systems have evolved from the past when informationbased controls started with the advent of computers. This led to the development of the SCADA systems, and later sophisticated databases and geographical information systems were added to create technology-based platforms for system management. When personal digital assistants became available around the turn of the century, they were widely used in control and data acquisition functions.

Currently, these technologies have advanced with the development of smartphones, smart meters, and improved process controls [14]. Toward the future, more automation, advanced use of information for system management tasks such as leak detection, and more attention to cybersecurity are expected. Additionally, user information is expected to improve substantially.

\section{Controls, Instruments, and Utilization of Smart Water Systems}

The advancement of technologies for instrumentation and controls is driving the trend toward smart systems in different sectors of the economy. The concept of smart systems is being applied in cities, for example with smart buildings and smart transportation systems, among others. All have similar attributes based on the availability of sensors, actuators, and controls of subsystems for functions such as lighting, energy management, scheduling, and more.

Advancement in control methods follows the availability of technologies but also learning and experience about successful strategies. For example, in the case of smart water systems, some computer-based simulation models have proved to be useful and effective, while others have been developed but discarded due to lack of practical application. A possible example of this situation is the use of control methods that seem promising but have high levels of complexity and maintenance requirements that create a risk of malfunction. The use of inflatable dams placed inside of combined sewers to control overflows seems to fit this category [15]. These were proposed 50 years ago in San Francisco, for example, to address the expensive and perplexing problem of the aging combined sewers. However, their application has been limited. 
While much of the interest in smart water systems has been driven by technologies and control methods, how customers use smart water information to help transform cities is more strategic. If the past is a guide to the future, it is expected that technologies and control methods will continue to advance incrementally, new business opportunities will be created, and experts and managers will continue to seek out new methods to experiment with them. Meanwhile, the benefits of these advances to customers and how the evolving smart systems are accepted and improve quality of life in cities remain larger questions. This issue is not limited to smart water systems, of course, because people today are confronted with a rapidly changing information environment which affects their daily lives in many ways.

\section{Economic Framework of Smart Water Systems}

An economic framework for smart water systems will involve the supply and demand for the public and private goods provided, their direct and indirect benefits and costs, and their linkages and impacts due to interdependences with other sectors. The organization of system management to facilitate collective action is also involved, as are social issues stemming from interactions with system customers and other stakeholders [16].

The demands for water, wastewater, stormwater, and recycled water services are different. The water supply and recycled water are commodities that can be sold like toll goods [17]. Most explanations of water sector demands focus on them, but the demands for other services must also be assessed. Wastewater service comprises carrying unwanted used water away from properties and requires paying a portion of the treatment and disposal. Stormwater service involves draining properties and public areas and paying to prevent pollution from urban runoff. The supply of each of these services involves a combination of responding to demands and meeting mandates.

The direct and indirect benefits and costs of the services stem from the demands that are to be met [18]. The benefits of water supply services involve applying the water for uses that range from meeting essential drinking water requirements to satisfying social needs, like health-related hygiene in the home. For wastewater, the direct benefit to customers is the removal of the unwanted residual water, and environmental protection is an indirect benefit. Stormwater services have multiple benefits, including protecting property and facilitating traffic movement in the city. Their multi-faceted attributes have made them a key part of a sustainability assessment protocol [19]. Taken together, the benefits from urban water services range across multiple categories and cannot be quantified easily.

The indirect benefits of urban water services demonstrate the connector roles of water services to various aspects of the economy and society. They stem from linkages and interdependencies with the other sectors, like employment, housing, energy supply, urban transportation, and the environment. Social impacts from water and its interactions can be considered indirect benefits and costs, and there is a substantial literature discussing how to define them [20].

Smart water systems will operate in the context of these interdependencies during normal and emergency times. For example, quality housing depends on meeting all water demands effectively during normal times. If there is a failure, the quality of the housing deteriorates. In the case of emergencies, the interdependencies can lead to systemic failures. For example, during flooding the failure of a stormwater system might trigger failure if the flooding shuts down a part of an electric power system [21].

The economic framework also involves the organization of urban water systems to facilitate effective operation and integration. The organization will depend on the structure of government and on public-private cooperation. Each of the services can be a separate utility or various degrees of consolidation and integration can be forged.

Finance is perhaps the most important issue in the economic framework of smart water systems. The management organizations can operate as utilities, but public goods are included among their services, and financing them may require subsidies along with fees for services. Each of the water services has its own financial structure. For example, 
water supply is like a public utility. Wastewater involves charges that are mandatory and may be offered like a utility, even if its services do not involve the distribution of a commodity. Stormwater has a unique financial structure and has been moving toward a utility model [22]. Recycled water is difficult to finance but is positioned as a utility to facilitate it [23].

By adding smart capabilities to integrated urban water systems new possibilities for effectiveness, equity, and reliability are created. Perhaps the greatest benefits are to fulfill demands more effectively and to extend services on a cost-effective basis to more people. Smart systems with their information and computing technologies should be able to promote integration through linkages for communication and controls [24]. By sensing the status of systems and their performance, greater reliability should be fostered [25].

In the category of improving performance by reducing failures, smart systems can monitor environmental water quality and water in piped systems to prevent exposure of people to negative situations [26]. Additionally, hydrometeorological sensing networks can provide advance notice of urban flood problems and warnings can be issued [27]. Blocking cyber terrorism is another potential benefit, although the smart capability added by linking the systems may open them to new possibilities for attack [28].

Urban customers can expect more information about total benefits from water services and they can learn more about the total picture of water in cities through education programs. They can also learn about water finance and conservation with information about their bills. Subject to privacy concerns, information can be extended down to the water use of individual fixtures by using the technology of the Internet of Things (IoT).

\section{Examples of Smart Integrated Water Systems}

The selection of brief case studies as examples is based on innovation and illustrates a range of situations. Singapore is one of the world's major cities, and it is chosen as the primary case study because it has developed its concepts comprehensively over a period of years. Paju Smart Water City in South Korea is smaller than Singapore and its experience is explained due to its connection with an evolving smart city. Fort Collins, Colorado is still smaller and considered a medium city in the United States that is evolving its smart systems in ways that are characteristic of leading-edge cities. Juarez, Mexico is a large city in an arid zone with major issues in sustaining an adequate water supply. It has used smart systems to address major issues of sustainability.

In Singapore, the imminent loss of its source of water motivated the city to create an integrated water system, and this led to the development of a "four taps" approach to water management that includes local catchments, imported water, reuse, and desalination. The four taps provide for integration of sources, reuse provides a link between water supply and wastewater infrastructure, and a separate stormwater system is also used [29].

Singapore's water agency (PUB) has explained its approach to smart water management [30]. The integration will connect the smart drainage grid, smart plants, smart water grid, and smart sewer grid. Technologies to enable the smart features will include machine learning for decision support systems, big data to provide insights about the system, the Internet of things to connect sensors and devices, process simulations for scenarios using digital twins, and robots or unmanned vehicles to perform manual tasks. Singapore anticipates using many smart features in its individual systems. For example, the drainage grid will have extensive hydrometeorological monitoring, the smart plants will feature automation, the smart water grid will include pressure flow and water quality, and the smart sewer grid will include illegal discharge tracing. When these features are fully operational, they will aid Singapore in its quest to be self-sufficient in water and to have greater water security.

Paju is a developing city in the northern part of South Korea, near the 38th parallel. Its population is about 425,000 , and it has been the focus of developing a smart water system with the sponsorship of K-Water, South Korea's national water agency. Paju has 
been explained as a case study is one of the selections in the study by the International Water Resources Association about smart water management.

Korea has devoted substantial attention to the development of improved integrated water management and the use of intelligent water resources operations technology to promote water security and improved operations [31,32]. This emphasis on using technology is carried out in conjunction with multiple objectives, such as water safety and security, and including a "tastier and healthier water supply". This requires the use of smart water management to provide real-time information about tap water quality to gain public trust. K-water is pursuing objectives to manage source water, optimize water treatment, operate intelligent networks, customize industrial water supply, and optimize wastewater treatment. These goals are translated into water quality management, water quantity management, risk management, energy management, pipe network analysis, and demand forecasting.

So far, the major accomplishments of the Paju Smart Water City Pilot Project focus on improving the reliability of tap water, better customer service, and relieving distrust by citizens of tap water. Prior to the project, only about $1 \%$ of the population used water for drinking, but after the project pilot project, this percentage increased to $36.3 \%$. Reports of satisfaction have also improved and the need for water purifiers will be significantly reduced.

Fort Collins, Colorado has an integrated utility where four services are managed together: water supply, wastewater, stormwater, and electric power. The city has recently completed a study of how to foster additional integration by linking raw irrigation water with its water supply system to utilize water sources and infrastructure better [33]. Fort Collins exhibits a small amount of water recycling, but its gravity water supply system would make it expensive to treat wastewater and pump it back uphill. Moreover, the water law system that operates in Colorado places certain barriers in place for water recycling.

The smart water features in the Fort Collins system are typical of those in US cities that are implementing new technologies. For example, the city has district metering areas with valves and remote pressure gauges, access to radar-based weather forecasting, and nondestructive sensors for main wastewater sewers. Fort Collins is customer friendly with its utility services and engages actively with water users by reporting about periodic water uses to encourage conservation. Fort Collins can access other technologies such as advanced metering infrastructure and real-time modeling for water distribution, and it implements them according to need.

The Juarez City case study addresses issues of a major metropolitan area in an arid zone. Juarez and El Paso are twin metropolitan areas coalescing as one urban region. Juarez draws its water from a binational aquifer in which management can be contentious [34]. The city has undertaken an aggressive smart water program based on measurement and control to interact with customers in proactive ways for water conservation. The features of the system are smart meters with high accuracy, pressure control valves, advanced metering infrastructure, and a web platform for customer outreach.

The project is to be self-funded and progress through 2021 has been promising. Implementation started with major users and will be extended to additional smart meter applications and system controls. The eventual goal is to eliminate most water losses, measure and manage water use carefully, and improve the capacity of the utility to continue to serve the growing city, despite water supply limitations.

More case studies are available, and a synthesis can be found in [2]. Many case studies of integrated approaches are also available [35]. The lessons learned converge on a few principal challenges. These will be summarized next, and future directions will be summarized afterward with the identification of trends that are evident from the cases.

\section{Challenges to Integration}

An understanding of significant barriers to implementing integrated and smart water systems has emerged from the pilot studies. Some of the challenges were summarized in the smart water management study by (IWRA, 2021), which had that as a goal. Other 
barriers have been identified through studies such as [36], which assessed studies about the implementation of integrated strategies. The understanding of challenges converges to a few main problems.

Most barriers to integration deal with organizational stovepipes and the difficulty in merging or even gaining cooperation among public organizations [37]. Another challenge is the complexity of integrated urban water systems, with their different levels of infrastructure and operations management and their separate regulatory structures. To move the needle will require transformations in institutional cultures to overcome resistance to change. Concessions may be needed to overcome resistance to integration. For example, participants in one case study overcame stovepipes partially by allowing the merged organizations to retain their separate SCADA systems.

In terms of implementing smart attributes, financial barriers were identified most often, with a focus on higher-than-expected costs and lower revenues than needed. Lack of financial support for demonstration and training was also mentioned. A related barrier was the large amount of time and institutional commitment required.

The institutional commitment required competes with other capacity issues, which also pose limiting factors for the implementation of smart systems. Capacity is needed among staff to plan and manage programs, as well as from support organizations to provide services and equipment. For example, in support organizations, the large-scale demand for the production of smart meters may be a constraint. On the utility side, the task of reducing staff positions that perform traditional but now outdated functions can be difficult. Additionally, other stakeholders such as allied agencies must have enough capacity to participate productively, to understand, and support the transition to smart systems.

The local nature of water systems and the diversity it creates constitutes a barrier because, even if an approach works in one place, it may not be possible to replicate it in another with different conditions. This means that pilot studies may have limited applicability, except for very specific components or practices in smart systems.

It is also difficult to assess the benefits of smart systems if incremental performance improvements and providing enhanced information to customers do not yield politically attractive results in the near term. This problem, when combined with the limited funding for smart systems, may defer programs indefinitely.

Given the problems in large cities, the greatest opportunities for innovation may be in small and medium-size cities where different approaches in governance are more feasible. A reality in the vision of integrated urban water systems is the case of struggling cities where public services fall way below minimum standards [38].

Smart water cities hold the potential to improve quality of life and urban environments anywhere in any place where effective governance is in place. When it is, it seems inevitable that urban water systems will change and their performance will respond to the felt needs of people in the cities and that smart systems can help to effect behavioral changes such as greater confidence in tap water for drinking, water conservation, greater use of recycling, and improved urban water environments.

The behavioral changes will occur as people learn more about their water systems, which can occur through the provision of more useful and effective information about the systems. People can learn about health effects, positive environmental management, and preparation for emergencies, among other water-related subjects.

The model shown in Figure 2 provides a way to forecast how these changes can occur. The primary driver will be user information for daily needs and emergency preparation. People have ongoing needs for quality drinking water service, responsible wastewater management, drainage of properties, and common areas. While they may take the services for granted in some cases, with creative approaches to water education, better cooperative arrangements between water managers and water users can take place.

Organizational and governance changes required to facilitate future improvements are likely, although in some situations progress may be slow. Resistance to change is as deep roots both on an individual and organizational basis. Possibility for improvements 
brought about by new technologies may drive change more rapidly than top-down political decisions intended to force changes prematurely. As new generations of water managers take the reins, they will be more familiar with technological possibilities and search for ways to change the way business is conducted.

With ongoing changes in technologies, it seems certain that unexpected possibilities will develop. The recent availability of social media, smart devices, wireless communications, machine learning, and others have ushered in management possibilities that were heretofore unknown. These have already changed many institutions and although urban water organizations may be slower and less agile than private businesses, they will change as well. The results should be positive to make systems more robust and reliable and for consumers is well, both in quality of service and in effectiveness.

Funding: This research received no external funding.

Institutional Review Board Statement: Not applicable.

Informed Consent Statement: Not applicable.

Data Availability Statement: Not applicable.

Conflicts of Interest: The author declares no conflict of interest.

\section{References}

1. IWA. The Journey to Water-Wise Cities. 2022. Available online: https://iwa-network.org/projects/water-wise-cities/ (accessed on 25 January 2022).

2. International Water Resources Association. Smart Water Management Case Study Report. 2021. Available online: https: //www.iwra.org/swm-2/ (accessed on 25 January 2022).

3. Loucks, D.P.; van Beek, E. Urban water systems. In Water Resource Systems Planning and Management; Springer: Cham, Switzerland, 2017. [CrossRef]

4. Zimmerman, R. Critical infrastructure and interdependency revisited. In The McGraw-Hill Homeland Security Handbook, 2nd ed.; Kamien, D.G., Ed.; The McGraw-Hill Companies: New York, NY, USA, 2012; pp. 437-460.

5. Nieuwenhuis, E.; Cuppen, E.; Langeveld, J.; de Bruijn, H. Towards the integrated management of urban water systems: Conceptualizing integration and its uncertainties. J. Clean. Prod. 2021, 280, 124977. [CrossRef]

6. US Water Alliance. One Water Roadmap. 2016. Available online: http://uswateralliance.org/sites/uswateralliance.org/files/ publications / Roadmap\%20FINAL.pdf (accessed on 25 January 2022).

7. Paulson, C.; Broley, W.; Stephens, L. Blueprint for One Water; Water Research Foundation: Denver, CO, USA, 2017.

8. LaFrance, D. Total water solutions: Caring about every drop, everywhere. J. Am. Water Works Assoc. 2013, 105, 6. [CrossRef]

9. American Planning Association. Integrated Water Resource Management. 2020. Available online: https://www.planning.org/ knowledgebase/watermanagement/ (accessed on 25 January 2022).

10. Gambrill, M.; Naughton, M.; Kirchner, L.; Goksu, A. Mainstreaming Water Resources Management in Urban Projects: Taking An Integrated Urban Water Management Approach. 2016. Available online: https://www.worldbank.org/en/topic/water (accessed on 25 January 2022).

11. Grigg, N.S. Integrated Water Resources Management: An Interdisciplinary Approach; Palgrave Macmillan: London, UK, 2016.

12. Ministry of Housing and Urban Affairs. What Do We Mean by a Smart City? 2022. Available online: https://smartcities.gov.in/ about-scm (accessed on 25 January 2022).

13. Anton, S.D.; Fraunholz, D.; Lipps, C.; Pohl, F.; Zimmermann, M.; Schotten, H.D. Two decades of SCADA exploitation: A brief history. In Proceedings of the IEEE Conference on Application, Information and Network Security, Miri, Malaysia, 13-14 November 2017. [CrossRef]

14. Sims, S. Evolving Control Systems are Key to Improved Performance. Control Engineering. 2021. Available online: https: //www.controleng.com/articles/evolving-control-systems-are-key-to-improved-performance/ (accessed on 25 January 2022).

15. Ridgway, K.; Rabbaig, M. Use of in-line inflatable dams for CSO control. Proc. Water Environ. Fed. 2006, 2006, 5578-5590. [CrossRef]

16. Noll, R. The Economics of Urban Water Systems. Thirsting for Efficiency: The Economics and Politics of Urban Water System Reform; Pergamon: Oxford, UK, 2002; pp. 43-63. [CrossRef]

17. House-Peters, L.A.; Chang, H. Urban water demand modeling: Review of concepts, methods, and organizing principles. Water Resour. Res. 2011, 47, W05401. [CrossRef]

18. Rietveld, L.C.; Siri, J.G.; Chakravarty, I.; Arsenio, A.M.; Biswas, R.; Chatterjee, A. Improving health in cities through systems approaches for urban water management. Environ. Health 2016, 15, S31. [CrossRef] [PubMed]

19. Institute for Sustainable Infrastructure. Envision Sustainable Infrastructure Framework. 2022. Available online: https:// sustainableinfrastructure.org/wp-content/uploads/EnvisionV3.9.7.2018.pdf (accessed on 25 January 2022). 
20. Cosgrove, W.J.; Loucks, D.P. Water management: Current and future challenges and research directions. Water Resour. Res. 2015, 51, 4823-4839. [CrossRef]

21. Narayanan, A.; Finucane, M.; Acosta, J.; Wicker, A. From awareness to action: Accounting for infrastructure interdependencies in disaster response and recovery planning. GeoHealth 2020, 4, e2020GH000251. [CrossRef]

22. Kane, J.; Shivaram, R. As Flood Risks Intensify, Stormwater Utilities Offer a More Resilient Solution. 2017. Available online: https: / / www.brookings.edu/blog/the-avenue/2017/09/21/as-flood-risks-intensify-stormwater-utilities-offer-a-moreresilient-solution/ (accessed on 25 January 2022).

23. De Paoli, G.; Mattheiss, V. Cost, Pricing and Financing of Water Reuse against Natural Water Resources. 2016. Available online: http: / / demoware.ctm.com.es/en/results/deliverables/deliverable-d4-7-cost-pricing-and-financing-of-water-reuseagainst-natural-water-resources.pdf/view (accessed on 25 January 2022).

24. Goldstein, P. Smart Water Technology: How IoT Helps Cities Save Money and Conserve Water. 2020. Available online: https:/ / statetechmagazine.com/article/2020/07/smart-water-technology-how-iot-helps-cities-save-money-and-conservewater-perfcon (accessed on 25 January 2022).

25. Moy de Vitry, M.; Schneider, M.Y.; Wani, O.F.; Manny, L.; Leitao, J.P.; Eggimann, S. Smart urban water systems: What could possibly go wrong? Environ. Res. Lett. 2019, 14, 081001. [CrossRef]

26. Cantor, A. Water Distribution System Monitoring: A Practical Approach for Evaluating Drinking Water Quality; Routledge: London, UK; Taylor \& Francis: Boca Raton, FL, USA, 2018.

27. Hénonin, J.; Russo, B.; Mark, O.; Gourbesville, P. Real-time urban flood forecasting and modelling-A state of the art. J. Hydroinformat. 2013, 15, 717-736. [CrossRef]

28. Clark, R.; Panguluri, S.; Nelson, T.; Wyman, R. Protecting drinking water utilities from cyberthreats. J. Am. Water Works Assoc. 2017, 109, 50-58. [CrossRef]

29. Tortajada, C. Singapore: An Exemplary Case for Urban Water Management. Case Study. $2006 . \quad$ Available online: https:/ / thirdworldcentre.org/wp-content/uploads/2020/07/RPP-Nov-6-06-Singapore-an-Exemplary-Case-for-UrbanWater-Management-Report.pdf (accessed on 25 January 2022).

30. PUB. Smart Water Management: Singapore's Experience. 2022. Available online: https://events.development.asia/system/files/ materials/2020/11/202011-smart-water-management-singapore-experience.pdf (accessed on 25 January 2022).

31. Yi, S.; Ryu, M.; Suh, J.; Kim, S.; Seo, S.; Kim, S. Smart Water Management: Application to Paju Smart Water City. 2021. Available online: https:/ / www.iwra.org/wp-content/uploads/2018/11/3-SWM-Paju-final.pdf (accessed on 25 January 2022).

32. Lee, S.-H. Global competition, smart water service. J. Water Policy Econ. 2015, 24.

33. Cole, J.; Sharvelle, S.; Fourness, D.; Grigg, N.; Roesner, L.; Haukaas, J. Evaluation of centralized and decentralized strategies for dual water supply: A case study. ASCE J. Water Resour. Plan. Manag. 2017, 144, 05017017. [CrossRef]

34. Ibáñez, O.; Lazo, J.; Meza, R.; Miranda, A. Juarez City, Mexico: Smart network for meter reading and pressure control management. In Proceedings of the World Water Congress XVII, Daegu, Korea, 29 November-3 December 2021; International Water Resources Association: Paris, France, 2021.

35. American Water Resources Association. Case Studies in Integrated Water Resources Management: From Local Stewardship to National Vision. 2013. Available online: https://inyo-monowater.org/wp-content/uploads/2012/11/AWRA-Case-StudiesIWRM.pdf (accessed on 25 January 2022).

36. Mukheibir, P.; Howe, C.; Gallet, D. Institutional issues for integrated 'One water' management. In Water Environment Research Foundation, Water Research Foundation and Water Research Australia; IWA Publishing: London, UK, 2015.

37. Entwistle, T.; Martin, S. From competition to collaboration in public service delivery: A new agenda for research. Pub. Adm. 2005, 83, 233-242. [CrossRef]

38. Tucci, C.E.M. Integrated Urban Water Management in Large Cities: A Practical Tool for Assessing Key Water Management Issues in the Large Cities of the Developing World. World Bank. 2009. Available online: https://collaboration.worldbank.org/ content/sites/collaboration-for-development/en/groups/tdlc-technical-deep-dive/groups/iuwm-south-south-knowledgeexchange/documents.entry.html/2019/01/23/general_iuwm-WqPt.html (accessed on 25 January 2022). 